\section{Rapid Paper}

\section{Inhibition of Platelet Aggregation by Dietary Linseed Oil}

\author{
Masataka IsHINAGA, Masanori KAKUTA, \\ Hiroshi NARITA and Makoto KITO
}

\author{
Research Institute for Food Science, \\ Kyoto University, Uji, Kyoto 611, Japan
}

Received October 29, 1982

Male Sprague-Dawley rats were fed diets containing linseed oil, safflower oil, or cacao butter for 27 weeks. The collagen-induced aggregation of washed platelets decreased only in rats fed linseed oil. Dietary oils did not influence the phospholipid composition of platelets, but did influence the fatty acid composition of platelet phospholipids. Compared with the other diets, the linseed oil diet markedly decreased the arachidonic acid content in platelet phosphatidylcholine and accumulated the eicosapentaenoic acid in all phospholipids. A similar change was not found in platelets from rats fed the other diets. These results indicate that the feeding of linseed oil, which has a high linolenic acid (a precursor of eicosapentaenoic acid) content, alters the fatty acid composition of platelet phospholipids similar to the feeding of fish oils, and thereby reduces the aggregation tendency of platelets.

The relationship between platelet function and dietary oils has been extensively investigated on the formation of thrombi. In general, saturated oils enhance platelet aggregation but polyunsaturated oils reduce it. ${ }^{1 \sim 5)}$ Eicosapentaenoic acid $(20: 5 \omega 3)$ from certain fish oil markedly reduces the incidence of cardiovascular disease in Greenland Eskimos by reducing the platelet aggregation tendency. ${ }^{6,7)}$ This fatty acid decreases thromboxane $\mathrm{A}_{2}$ production, which causes platelet aggregation, by inhibiting the cyclooxygenase reaction competitively with the natural substrate, arachidonic acid $\left.(20: 4 \omega 6){ }^{8}\right)$ These fatty acids are supplied from the platelet membrane phospholipids. However, it is still uncertain how the fatty acids of platelet membrane phospholipids modified by dietary oils can affect the platelet aggregation.

From these points of view, we have investigated the effects of dietary oils on platelet aggregation by using washed platelets to correlate this aggregation to changes in platelet phospholipids. The mechanism of arachidonic acid release from the platelet membrane is discussed on the basis of precise analysis of the fatty acid composition of platelet phospholipids modified by dietary oils.

\section{MATERIALS AND METHODS}

Animals and diets. Male Sprague-Dawley rats (5 weeks old) were used. The basal diet was prepared with the following weight percentage composition: vitamin-free casein 25 , corn starch 38 , sucrose 21 , salt mixture 6 , vitamin mixture 2 , and cellulose powder 8 . Linseed oil (LSO), safflower oil (SO), or cacao butter (CB) was supplemented to account for $20 \%(\mathrm{w} / \mathrm{w})$. The fatty acid composition of these oils was determined (Table I). To $1 \mathrm{~kg}$ of the LSO- or SO-diet, $250 \mathrm{mg}$ of tocopherol and $500 \mathrm{mg}$ of butylated hydroxytoluene (BHT) were added. The low fat diet (LF) contained $10 \%$ of sucrose and $10 \%$ of corn starch in place of $20 \%$ of oil. The diets were fed $\mathrm{ad}$ libitum to 4 groups of 15 rats each for 27 weeks.

Preparation of washed platelets. The animals were anesthetized with ether, and blood was collected from the abdominal aorta in the presence of acid citrate dextrose $10 \%(\mathrm{v} / \mathrm{v})$. Blood $(11 \sim 13 \mathrm{ml})$ from one or more rats was centrifuged at $800 \times g$ for $10 \mathrm{~min}$, after which the supernatant was recentrifuged at $100 \times g$ for $10 \mathrm{~min}$. The resulting supernatant, platelet-rich plasma (PRP), was centrifuged at $1000 \times g$ for $10 \mathrm{~min}$ and the platelets derived were washed with $\mathrm{Ca}^{2+}$-free Tyrode solution containing $0.25 \%$ of gelatin, $\mathrm{pH} 6.6$, and resuspended in the Tyrode solution, $\mathrm{pH} 7.4$.

TABle I. Fatty Acid Composition of Dietary Oils

\begin{tabular}{lccc}
\hline Fatty acid & $\begin{array}{c}\text { Linseed } \\
\text { oil }\end{array}$ & $\begin{array}{c}\text { Safflower } \\
\text { oil } \\
\%(\mathrm{w} / \mathrm{w})\end{array}$ & $\begin{array}{c}\text { Cacao } \\
\text { butter }\end{array}$ \\
\hline $16: 0^{a}$ & 6.3 & 6.8 & 26.4 \\
$18: 0$ & 3.5 & 2.3 & 31.0 \\
$18: 1(\omega 9)$ & 17.2 & 12.8 & 37.7 \\
$18: 2(\omega 6)$ & 15.7 & 77.9 & 3.8 \\
$18: 3(\omega 3)$ & 57.3 & $\mathrm{~T}$ & $\mathrm{~T}$ \\
\hline
\end{tabular}

$\mathrm{T}$, trace amounts (less than $1 \%$ ).

a The first number gives the number of carbon atoms in the fatty acid molecule. The second indicates the number of double bonds. $\omega$ indicates the position of the first double bond in relation to the methyl end of the fatty acid molecule. 
Lipid analysis. The platelet suspension from 3 or 4 rats was added to cold chloroform/methanol $(1: 2, \mathrm{v} / \mathrm{v})$ containing $0.001 \%$ of BHT and $0.1 \mathrm{~mm}$ tocopherol, and lipids from the platelets were extracted by the method of Arthur and Sheltawy, ${ }^{9)}$ in which the water was replaced with $2 \mathrm{M}$ $\mathrm{KCl}$ and $0.1 \mathrm{M}$ EDTA. The separation and determination of the phospholipids have been described previously. ${ }^{10}$ ) Phosphatidylethanolamine (PE) was methylated with boron trifluoride/methanol and the other phospholipids with $0.5 \mathrm{~N}$ sodium methoxide/methanol (Applied Science Lab. Inc., Penn., USA). The analysis of the fatty acid methylesters has been described previously. ${ }^{10)}$ The identification was accomplished by GLC-mass spectrometry. All developing solvents contained $0.01 \%$ of BHT.

Other analysis. Statistical analysis was performed with Student's $t$ test. Phosphorus was determined according to the method of Bartlett ${ }^{11)}$ and Keenan et al. ${ }^{12)}$

\section{RESULTS AND DISCUSSION}

\section{Aggregation of washed platelets}

Many factors such as collagen, ADP, thrombin, and platelet activating factor, are concerned in platelet aggregation during hemostasis. Collagen was used as an aggregating reagent, since it is thought to be the initial, and therefore most important, stimulus. The tendency for aggregation of PRP of rats fed oils was significantly lower than that of rats fed the LF-diet ( $p<0.01$, data not shown). The aggregation tendency of washed platelets was similar among rats fed the LF-, SO-, and CBdiets, whereas it was significantly reduced in rats fed the LSO-diet (about $38 \%, p<0.01$ ) (Fig. 1). This indicates that only in the case of the LSO-diet is alteration in the platelet aggregation ability attributable to the modification of platelet phospholipids. Hornstra and Haddeman have shown that PRP aggregation of rats fed hydrogenated coconut oil is lower than that of rats fed linseed or sunflower oils. ${ }^{13)}$ However, experiments using washed platelets were not carried out in this case.

\section{Effects of dietary oils on platelet phospholipids}

The phospholipid composition of the platelets did not change after feeding of various oils for 27 weeks (Table II). The fatty acid composition of the various platelet phospholipid classes, however, was differentially affected by

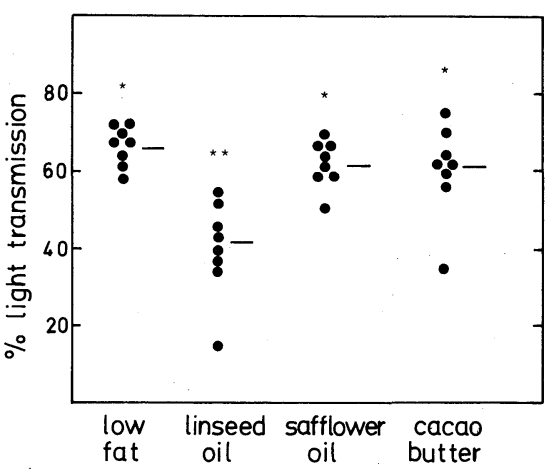

FIG. 1. Collagen-induced Aggregation of Washed Platelets.

Platelet number was adjusted to $2 \times 10^{8} / 0.2 \mathrm{ml}$. One $\mu \mathrm{g}$ of collagen (Horn-Chemie, Munchen, West Germany), was used as an aggregating reagent. The extent of aggregation was measured as the maximum transmission of light (in percent) by using Tyrode solution as the control in a platelet aggregation tracer (Model PAT-2M, Niko Bioscience Co. Ltd., Japan). The different asterisks are significantly different $(p<0.01)$.

dietary oils (Table III). The major changes in fatty acid composition by LSO-diet are important to explain its inhibitory effect on platelet aggregation. The LSO-diet accumulated $18: 2 \omega 6$ but reduced $20: 4 \omega 6$ levels in all phospholipids except phosphatidylinositol (PI). The reduction of $20: 4 \omega 6$ in PC was notable. In addition $20: 5 \omega 3$ was significantly accumulated in all phospholipids. Sanders et al. have also observed the accumulation of $20: 5 \omega 3$ in total phospholipids of human platelets by a dietary supplement of LSO. ${ }^{14)}$ This suggests that the conversion of $18: 3 \omega 3$ to $20: 5 \omega 3$ precedes that of $18: 2 \omega 6$ to $20: 4 \omega 6$ according to a higher affinity of the $\omega 3$ family to desaturation and elongation enzymes.

In a cyclooxygenase reaction, the substrate $20: 4 \omega 6$ is supplied from phospholipid in the platelet membranes. Two alternative pathways are proposed in this mechanism: 1) phospho-

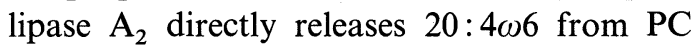
and/or $\mathrm{PE}^{15,16)}$; 2) phospholipase $\mathrm{C}$ specific for PI initially makes diglyceride from PI and $20: 4 \omega 6$ is then released from diglyceride ${ }^{17,18}$ ) or phosphatidic acid. ${ }^{19)}$ Inhibition of the cyclooxygenase reaction by $20: 5 \omega 3$ is competitive with $20: 4 \omega 6$, and its affinity to the en- 
zyme seems to be equal to that of $20: 4 \omega 6 .^{8)}$ In addition, the product thromboxane $A_{3}$ has little effect on platelet aggregation. ${ }^{20)}$ Therefore, the inhibition of platelet aggregation by $20: 5 \omega 3$ may be attributed to dilution of the effective free $20: 4 \omega 6$ by $20: 5 \omega 3$. We can calculate the dilution effect by $20: 5 \omega 3$ $(20: 5 \omega 3 / 20: 4 \omega 6+20: 5 \omega 3)$ in individual phospholipids from Table III; 0.38, 0.28, and
0.12 for $\mathrm{PC}, \mathrm{PE}$, and $\mathrm{PI}$, respectively. The inhibition of platelet aggregation (about 38\%) observed in a LSO-diet suggests that PC and/or PE are the principal donors of $20: 4 \omega 6$, since the $20: 5 \omega 3$ content in PI is too small to explain the degree of inhibition. Recently, Hornstra et al. or Siess et al. have indicated that $20: 5 \omega 3$ inhibited the formation of thromboxan $\mathrm{A}_{2}$ from $20: 4 \omega 6$ in the platelets of rats

Table II. Phospholipid Composition of Platelets

Values are means \pm SE of 4 samples composed of 3 or 4 rats.

\begin{tabular}{|c|c|c|c|c|}
\hline \multirow[b]{2}{*}{ Phospholipid } & \multicolumn{4}{|c|}{ Dietary oils } \\
\hline & \multicolumn{3}{|c|}{$\%(\mathrm{~mol})$} & Cacao butter \\
\hline Lysophosphatidylcholine & $2.8 \pm 0.6$ & $3.7 \pm 0.5$ & $2.8 \pm 0.2$ & $2.7 \pm 0.4$ \\
\hline Sphingomyelin & $9.6 \pm 1.0$ & $11.1 \pm 0.3$ & $10.6 \pm 0.6$ & $11.7 \pm 0.7$ \\
\hline Phosphatidylcholine & $43.1 \pm 1.9$ & $39.2 \pm 0.6$ & $39.2 \pm 1.2$ & $39.8 \pm 0.9$ \\
\hline Phosphatidylserine & $11.4 \pm 0.8$ & $12.5 \pm 0.5$ & $12.4 \pm 1.1$ & $11.5 \pm 0.9$ \\
\hline Phosphatidylinositol & $2.3 \pm 0.4$ & $2.1 \pm 0.2$ & $2.5 \pm 0.4$ & $2.4 \pm 0.3$ \\
\hline Phosphatidylethanolamine & $29.6 \pm 1.7$ & $30.9 \pm 0.4$ & $31.7 \pm 0.6$ & $31.4 \pm 1.2$ \\
\hline
\end{tabular}

Table III-1. Fatty Acid Composition of Platelet Phosphatidylcholine and Phosphatidylethanolamine

Values are means \pm SE of 4 samples composed of 3 or 4 rats. Values with a different superscript letter are significantly different $(p<0.05)$.

\begin{tabular}{|c|c|c|c|c|c|c|c|c|}
\hline \multirow{3}{*}{$\begin{array}{l}\text { Fatty } \\
\text { acid }\end{array}$} & \multicolumn{2}{|c|}{ Low fat } & \multicolumn{2}{|c|}{ Linseed oil } & \multicolumn{2}{|c|}{ Safflower oil } & \multicolumn{2}{|c|}{ Cacao butter } \\
\hline & $\mathrm{PC}$ & $\mathrm{PE}$ & $\mathrm{PC}$ & $\mathrm{PE}$ & $\mathrm{PC}$ & $\mathrm{PE}$ & $\mathrm{PC}$ & PE \\
\hline & \multicolumn{2}{|c|}{$\%(\mathrm{w} / \mathrm{w})$} & \multicolumn{2}{|c|}{$\%(w / w)$} & \multicolumn{2}{|c|}{$\%(w / w)$} & \multicolumn{2}{|c|}{$\%(w / w)$} \\
\hline $16: 0^{*}$ & - & $6.9 \pm 0.1$ & - & $6.6 \pm 0.2$ & - & $5.7 \pm 0.2$ & - & $6.0 \pm 0.1$ \\
\hline $16: 0$ & $57.8 \pm 0.6$ & $5.3 \pm 0.1$ & $56.1 \pm 1.1$ & $5.1 \pm 0.1$ & $56.1 \pm 2.1$ & $4.5 \pm 0.1$ & $53.2 \pm 0.2$ & $3.6 \pm 0.1$ \\
\hline $16: 1$ & $4.4 \pm 0.1$ & - & $1.4 \pm 0.3$ & - & $\mathrm{T}$ & - & $\mathrm{T}$ & - \\
\hline $18: 0^{*}$ & - & $7.5 \pm 0.1$ & - & $9.1 \pm 0.4$ & - & $7.6 \pm 0.3$ & - & $11.4 \pm 0.0$ \\
\hline $18: 0$ & $6.5 \pm 0.3$ & $13.8 \pm 0.7$ & $8.9 \pm 0.5$ & $14.5 \pm 0.7$ & $9.0 \pm 0.3$ & $12.4 \pm 0.3$ & $10.7 \pm 0.2$ & $12.7 \pm 0.3$ \\
\hline $18: 1^{*}$ & - & $7.5 \pm 0.1$ & - & $4.3 \pm 0.1$ & - & $3.0 \pm 0.1$ & - & $3.5 \pm 0.1$ \\
\hline $18: 1(\omega 9)$ & $15.8 \pm 0.2$ & $7.2 \pm 0.2$ & $7.6 \pm 0.1$ & $5.3 \pm 0.1$ & $5.8 \pm 0.3$ & $5.6 \pm 0.1$ & $12.3 \pm 0.4$ & $4.2 \pm 0.3$ \\
\hline $18: 2(\omega 6)$ & $2.0 \pm 0.1$ & - & $14.6 \pm 0.3$ & $5.7 \pm 0.1$ & $13.1 \pm 0.4$ & $3.9 \pm 0.1$ & $3.2 \pm 0.1$ & $\mathrm{~T}$ \\
\hline $18: 3 .(\omega 3)$ & - & - & $2.3 \pm 0.1$ & $1.3 \pm 0.1$ & - & - & - & - \\
\hline $20: 2$ & - & - & - & - & $2.3 \pm 0.2$ & - & - & - \\
\hline $20: 3(\omega 9)$ & $3.6 \pm 0.1$ & $11.4 \pm 0.2$ & - & - & - & - & $1.1 \pm 0.0$ & $2.9 \pm 0.3$ \\
\hline $20: 3(\omega 6)$ & - & - & - & - & $T$ & $2.5 \pm 1.4$ & $\mathrm{~T}$ & $3.4 \pm 1.3$ \\
\hline $20: 4(\omega 6)$ & $8.6 \pm 0.4^{\mathrm{a}}$ & $28.6 \pm 0.5^{\mathrm{b}}$ & $4.8 \pm 0.4^{\mathrm{c}}$ & $25.7 \pm 0.7^{b}$ & $11.9 \pm 0.8^{\mathrm{d}}$ & $34.8 \pm 0.8^{\mathrm{e}}$ & $15.9 \pm 0.2^{\mathrm{d}}$ & $37.2 \pm 0.0^{\mathrm{e}}$ \\
\hline $20: 5(\omega 3)$ & - & - - & $2.9 \pm 0.3$ & $10.1 \pm 0.8$ & - & - & - & - \\
\hline $22: 3$ & - & $6.1 \pm 0.3$ & - & $\mathrm{T}$ & - & $1.2 \pm 0.4$ & - & $3.0 \pm 0.1$ \\
\hline $22: 4$ & - & $3.5 \pm 0.1$ & - & $2.2 \pm 0.2$ & - & $15.8 \pm 0.1$ & - & $10.4 \pm 0.3$ \\
\hline $22: 5$ & $\mathrm{~T}$ & $\mathrm{~T}$ & $1.3 \pm 0.1$ & $8.8 \pm 0.6$ & - & $\mathrm{T}$ & - & $1.7 \pm 0.3$ \\
\hline $22: 6$ & - & $\mathrm{T}$ & - & $1.2 \pm 0.1$ & - & $1.0 \pm 0.0$ & - & $\mathrm{T}$ \\
\hline
\end{tabular}

* Dimethylacetal derivatives of aldehydes.

$\mathrm{T}$, trace amounts (less than $1 \%$ ); PC, phosphatidylcholine; PE, phosphatidyletanolamine. 
Table III-2. Fatty Acid Composition of Platelet Phosphatidylinositol AND PhOSPHATIDYLSERINE

Superscript letters: see footnote to Table III-1.

\begin{tabular}{|c|c|c|c|c|c|c|c|c|}
\hline \multirow{3}{*}{$\begin{array}{c}\text { Fatty } \\
\text { acid }\end{array}$} & \multicolumn{2}{|c|}{ Low fat } & \multicolumn{2}{|c|}{ Linseed oil } & \multicolumn{2}{|c|}{ Safflower oil } & \multicolumn{2}{|c|}{ Cacao butter } \\
\hline & PI & PS & PI & PS & PI & PS & PI & PS \\
\hline & \multicolumn{2}{|c|}{$\%(w / w)$} & \multicolumn{2}{|c|}{$\%(w / w)$} & \multicolumn{2}{|c|}{$\%(w / w)$} & \multicolumn{2}{|c|}{$\%(w / w)$} \\
\hline $16: 0$ & $4.0 \pm 0.7$ & $1.3 \pm 0.1$ & $3.4 \pm 0.4$ & $1.0 \pm 0.1$ & $3.1 \pm 0.5$ & $1.0 \pm 0.2$ & $3.0 \pm 0.1$ & $1.0 \pm 0.0$ \\
\hline $16: 1$ & $1.0 \pm 0.1$ & $1.0 \pm 0.2$ & $\overline{\mathrm{T}}$ & $\overline{\mathrm{T}}$ & $1.4 \pm 0.0$ & $\overline{\mathrm{T}}$ & $2.3 \pm 0.2$ & $1.0 \pm 0.0$ \\
\hline $18: 0$ & $28.8 \pm 1.1$ & $33.4 \pm 1.3$ & $33.8 \pm 1.0$ & $35.6 \pm 0.8$ & $33.0 \pm 0.6$ & $35.3 \pm 0.6$ & $36.5 \pm 0.6$ & $35.0 \pm 0.5$ \\
\hline $18: 1(\omega 9)$ & $6.9 \pm 0.7$ & $13.0 \pm 0.2$ & $5.6 \pm 0.2$ & $7.7 \pm 0.2$ & $4.2 \pm 0.2$ & $5.0 \pm 0.2$ & $7.2 \pm 0.2$ & $9.1 \pm 0.6$ \\
\hline $18: 2(\omega 6)$ & $1.1 \pm 0.0$ & - & $1.7 \pm 0.2$ & $11.0 \pm 0.8$ & $3.3 \pm 0.3$ & $5.8 \pm 0.4$ & $1.0 \pm 0.1$ & $3.1 \pm 0.2$ \\
\hline $18: 3(\omega 3)$ & - & - & - & $1.1 \pm 0.2$ & - & $1.0 \pm 0.0$ & - & - \\
\hline $20: 0$ & - & $2.2 \pm 0.1$ & - & - & - & - & - & - \\
\hline $20: 1$ & $1.6 \pm 0.6$ & $1.9 \pm 0.4$ & - & - & - & - & - & $1.4 \pm 0.0$ \\
\hline $20: 2$ & - & - & - & - & $1.0 \pm 0.1$ & $3.6 \pm 0.0$ & - & -- \\
\hline $20: 3(\omega 9)$ & $15.0 \pm 0.2$ & $11.9 \pm 0.9$ & - & - & - & - & - & $3.4 \pm 0.4$ \\
\hline $20: 3(\omega 6)$ & - & - & $2.1 \pm 0.4$ & $3.0 \pm 0.1$ & $1.5 \pm 0.3$ & $2.0 \pm 0.1$ & $3.2 \pm 0.4$ & $2.0 \pm 0.1$ \\
\hline $20: 4(\omega 6)$ & $34.3 \pm 1.3^{\mathrm{a}}$ & $26.4 \pm 0.2^{\mathrm{b}}$ & $42.2 \pm 1.3^{\mathrm{c}}$ & $26.7 \pm 1.0^{\mathrm{b}}$ & $51.0 \pm 1.5^{\mathrm{d}}$ & $40.1 \pm 0.3^{\mathrm{e}}$ & $42.7 \pm 1.5^{\mathrm{c}}$ & $35.9 \pm 0.7^{\mathrm{a}}$ \\
\hline $20: 5(\omega 3)$ & - & - & $5.9 \pm 0.6$ & $3.4 \pm 0.3$ & - & - & - & - \\
\hline $22: 0$ & - & - & - & $2.1 \pm 0.1$ & - & - & - & - \\
\hline $22: 3$ & $7.1 \pm 0.1$ & $7.4 \pm 1.0$ & $\mathrm{~T}$ & $\mathrm{~T}$ & $2.0 \pm 0.3$ & $\mathrm{~T}$ & $2.8 \pm 0.4$ & $3.8 \pm 0.6$ \\
\hline $22: 4$ & $1.9 \pm 0.4$ & $1.5 \pm 0.3$ & $3.0 \pm 0.6$ & - & $3.0 \pm 0.2$ & $5.5 \pm 0.6$ & $1.8 \pm 0.1$ & $2.9 \pm 0.1$ \\
\hline $22: 5$ & - & - & - & $6.2 \pm 0.3$ & - & $\mathrm{T}$ & - & $1.0 \pm 0.1$ \\
\hline $24: 0$ & - & - & - & $1.6 \pm 0.1$ & - & - & - & - \\
\hline
\end{tabular}

PI, phosphatidylinositol; PS, phosphatidylserine.

fed cod liver oil, or in the platelets of men taking mackerel diet. ${ }^{21,22)}$ However, the fatty acid composition of individual phospholipids remains unknown.

\section{REFERENCES}

1) G. Hornstra, "The Role of Fats in Human Nutrition," ed. by A. J. Vergroesen, Academic Press Inc., London, 1975, pp. 303 330.

2) J. A. Jakubowski and N. G. Ardlie, Atherosclerosis, 31, 335 (1978).

3) E. Berlin, E. J. Matsik, Jr. and C. Young, Jr., Lipids, 15, 604 (1980).

4) L. McGregor, R. Morazain and S. Renaud, Lab. Invest., 43, 438 (1980).

5) G. Galli, E. Agradi, A. Petron and E. Tremoli, Lipids, 16, 165 (1981).

6) J. Dyerberg, H. O. Bang, E. Stroffersen, M. Moncada and J. R. Vane, Lancet, i, 117 (1978).

7) H. O. Bang and J. Dyerberg, "Advances in Nutritional Research,” Vol. 3, ed. by H. H. Draper, Plenum Press, New York, 1980, pp. 1 22.

8) P. Needleman, A. Raz, M. S. Minkes, J. A. Ferrendelli and H. Sprecker, Proc. Natl. Acad. Sci. U.S.A., 76, 944 (1979).

9) G. Arthur and A. Sheltawy, Biochem. J., 191, 523
(1980).

10) S. Yasuda, Y. Kitagawa, E. Sugimoto and M. Kito, J. Biochem., 87, 1511 (1980).

11) G. R. Bartlett, J. Biol. Chem., 234, 466 (1959).

12) R. W. Keenan, G. Schmidt and T. Tanaka, Anal. Biochem., 23, 555 (1968).

13) G. Hornstra and E. Haddeman, Recent Prog. Cell Biol., 45, 9 (1978).

14) T. B. A. Sanders and K. M. Younger, Br. J. Nutr., 45, 613 (1981).

15) M. L. McKean, J. B. Smith and M. J. Silver, J. Biol. Chem., 256, 1522 (1981).

16) R. W. Walenga, E. E. Opas and M. B. Feinstein, $J$. Biol. Chem., 256, 12523 (1981).

17) S. Rittenhouse-Simmons, J. Clin. Invest., 63, 580 (1979).

18) R. L. Bell, D. A. Kennerly, N. Stanford and P. W. Majerus, Proc. Natl. Acad. Sci. U.S.A., 76, 3238 (1979).

19) M. M. Billah, E. G. Lapetina and P. Cuatrecasas, $J$. Biol. Chem., 256, 5399 (1981).

20) A. Raz, M. S. Minks and P. Needleman, Biochim. Biophys. Acta, 448, 305 (1977).

21) G. Hornstra, E. Christ-Hazelhof, E. Haddeman, F. ten Hoor and D. H. Nugteren, Prostaglandins, 21, 727 (1981).

22) W. Siess, P. Roth, B. Scherer, I. Kurzmann, B. Böhling and P. C. Weber, Lancet, i, 441 (1980). 